\title{
Clasificaciones Urbanas en Andalucía. Las Ciudades Medias
}

\author{
Gabriel CANO GARCÍA*
}

\section{RESUMEN}

Se trata de hacer una puesta a punto de estudios sobre clasificaciones urbanas, especialmente ciudades medias de Andalucía, incluyendo las aportaciones del autor desde hace dos décadas. Después se realiza una nueva propuesta, compaginando límites demográficos con criterios territoriales y analizando los núcleos de espacios y comarcas de Andalucía. Antes, recordamos una breve historia de nuestras ciudades y la importancia de las mismas.

\section{ABSTRACT}

The main aim of this article is the fine-tuning of different studies about urban classifications, basically medium-sized cities in Andalusia, including author's reflections on this theme from the last two decades. It is also included a new approach, considering borders with territorial criteria and analysing the population centres of spaces and counties in Andalusia. Before, the article concentrates on a brief history of our cities and their importance.

\footnotetext{
* Catedrático de Análisis Geográfico Regional. Universidad de Sevilla y Director del Instituto de Desarrollo Regional, Fundación Universitaria.
} 


\section{INTRODUCCIÓN}

El estudio de las ciudades cuenta con una larga tradición en varias ciencias y, especialmente, en Geografía, donde se consideran distintas variables: la situación y el emplazamiento (poco desarrollados por cierto, cuando es precisamente la valoración más territorial), la evolución, la población, las funciones (actividades económicas, administración y otros servicios, etc.), las áreas de influencia, el plano y los paisajes urbanos, el planeamiento, el sistema de ciudades y la ordenación del espacio. Esta última cuestión proporciona buenas aportaciones a la articulación territorial, puesto que, en un esquema ya clásico, las ciudades constituyen los nodos o puntos espaciales en los que confluyen las líneas o ejes de infraestructuras con áreas intermedias (agrarias, forestales...) y, algo que debería añadirse al esquema: las divisiones para una mejor organización y desarrollo. Sin embargo, es verdad que en algunos casos la imagen de núcleo se va transformando en aglomeraciones y áreas metropolitanas.

En el sistema de ciudades hay una parte de clasificación, susceptible de enfoques diferentes, y un conjunto de urbes medias, con significación y funciones importantes, por lo que se pretende en este escrito avanzar con relación a lo que presentamos en otras ocasiones desde hace dos décadas, teniendo en cuenta también otros estudios. Todo ello, referido a Andalucía, donde el hecho urbano, y en concreto las ciudades medias, adquiere gran relevancia, porque siempre ha habido un alto grado de urbanización y han convivido pueblos y cortijos con ciudades importantes y también con núcleo medios, denominados agrociudades, fenómeno propio de esta Comunidad. Se pretende una puesta a punto de lo publicado sobre límites, no sólo demográficos, y clasificaciones, en especial las referidas a ciudades medias de Andalucía. Después se realiza una nueva propuesta con criterios territoriales $y$, antes, recordamos una breve historia de nuestras ciudades y la importancia de estas mismas.

\section{NOTAS SOBRE EVOLUCIÓN Y ACTUALIDAD DEL SISTEMA URBANO ANDALUZ}

La situación estratégica de Andalucía, entre continentes y mares, en un lugar de encrucijada con abundantes recursos (valles, campiñas, minas, madera, costas, 
un gran río navegable...), que desde antiguo desarrollaron técnicas punteras, explican crecimientos demográficos de pueblos y ciudades. Así, cuenta con una rica historia: Turdetania, heredera de Tartessos, la Bética, que añade a las ciudades preexistentes otras, componiendo una poderosa red, a cuya cabeza figuraba Córdoba, en el centro del Valle del Guadalquivir, cruce de caminos y junto a ricas campiñas. Después, tres núcleos cabeceras de conventos jurídicos: Sevilla (que integraba a Carmona, Ronda, Osuna, Coria, Alcalá del Río y Lora, entre otros núcleos), Cádiz (cuyo distrito litoral llegaba hasta Almería, con urbes como Málaga, Almuñécar y Adra), Écija (con un territorio introducido en la Depresión Intrabética, con Estepa, Antequera, Granada...) y, como núcleos más importantes de la parte oriental, Baza, Guadix y Vera.

Al-Ándalus supone una continuación y potenciación del sistema urbano andaluz, de manera que Córdoba se convierte en la capital de un estado independiente incluso en lo religioso, constituyendo una de las ciudades más pobladas, ricas y cultas del mundo conocido. Y la organización administrativa en coras incrementa la centralidad de sus capitales y de las cabeceras de distritos o iclims. A las mencionadas antes, se añaden como núcleos importantes Jaén, Onuba (Huelva), Algeciras, principal puerto de conexión con el norte de África, Jerez, Niebla, Almonte, Lepe, Arcos, Medina Sidonia, Morón, Osuna, Utrera, Alcalá de Guadaíra, Almodóvar, Lucena, Cabra, Priego, Baena, Porcuna, Huelma, Andújar, Martos, Baeza, Úbeda, Pechina, Purchena, Loja, Alhama, Archidona, Fuengirola, Motril... Los reinos andaluces en época almohade tenían como capitales a Sevilla, Córdoba, Jaén, Granada, Almería y Málaga, y hoy quedan numerosas huellas en el trazado callejero de cascos antiguos y en los paisajes urbanos, constituyendo un importante legado y un atractivo turístico (Alhambra, Mezquita, Giralda, Alcazabas, castillos, restos de mezquitas, iglesias mudéjares...).

La conquista castellana, primero del Valle y luego del reino de Granada (casi en el $\mathrm{XVI}$ ), supone un retroceso urbano y un aumento de la agrarización. Decaen la industria, el comercio y las funciones administrativas de las ciudades, destacando las cuatro capitales de los reinos (Sevilla, Córdoba Jaén y Granada), si bien las relaciones con el continente americano animan la economía y el desarrollo de algunas poblaciones. En el siglo XVIII se construyen infraestructuras y obras públicas que benefician al sistema urbano, y en el Censo de Floridablanca de 1789 hay bastante información, cartografiada y comentada por CANO en el tomo quinto de la Gran Enciclopedia Andaluza de la editorial Tartessos, 2000-2003. 
En 1787 (CANO, 2006), sólo había nueve ciudades con más de 20.000 habitantes, cinco capitales (Sevilla, Málaga, Granada, Córdoba y Cádiz) más Jerez, Écija, San Fernando y Antequera. Pero la cartografía de los núcleos superiores a 5.000 presentan un sistema que se aproxima al de fechas recientes con una buena dispersión de núcleos de tipo medio. La provincialización de 1833 refuerza a las ocho capitales, que desde entonces acumulan funciones administrativas, de servicios públicos y otras actividades (comerciales, industriales, turismo más tarde, etc.), que explican altos crecimientos demográficos posteriores. Pero en 1842 (CANO, 2006) aún no se notaban los efectos de las divisiones de 1833 y en la cabecera del sistema continúan las cinco capitales citadas, mientras que San Fernando y Antequera bajan de los 20.000. De nuevo se debe apelar a límites demográficos más bajos para que la comprensión del sistema urbano sea real.

Esa provincialización y la red de ferrocarriles dan lugar a desplazamientos del campo a la ciudad, que se incrementan a partir de los años cincuenta-setenta del siglo $X X$, en que se produjo un éxodo rural que dio lugar a una fuerte emigración andaluza a Cataluña, Madrid, País Vasco y al extranjero, pero, también, de los pueblos a las ciudades más próximas, especialmente a las capitales de provincia.

En los últimos años ha habido (salvo en Córdoba y Jaén) una constante bajada demográfica en los municipios capitalinos en beneficio de la periferia metropolitana; y una disminución de las distancias con respecto a la segunda ciudad de cada circunscripción (cuadro 1), a la vez que aumenta considerablemente la población de los núcleos con más de 20.000 habitantes: 1950, el 43.2\%; y 2005, el 65.3. Claro que no sólo cuentan la capital y el segundo núcleo de la provincia, sino que el sistema urbano es más amplio y se determina por otros criterios y variables que no son sólo los demográficos, cuestión que abordaremos después. En cualquier caso, hay una clara desconcentración del sistema urbano junto con el crecimiento de áreas metropolitanas y aglomeraciones, un tanto parado por la crisis actual.

Según un estudio anterior a esta crisis (SERRANO, 2007), Andalucía cuenta con cuatro aglomeraciones urbanas (AA.UU), de un total de 17, que en el 2006 suponen casi la mitad de la población (el $47.77 \%$ ), en crecimiento constante desde hace tiempo (en 1950, el 30.42; 1970, el 43.26), pero también ralentizado recientemente $(1991,47.56)$. Son las de Sevilla $(1.224 .555$ h., cuarto lugar, tras 
Madrid, Barcelona y Valencia), Málaga-Costa del Sol (1.178.951 h., quinto lugar), Cádiz-Jerez (617.488 h.) y Granada (15 puesto con 478.928 h.). Forman un conjunto andaluz de AA.UU muy bien definido en el Estado.

\section{CUADRO 1.}

\begin{tabular}{|l|l|l|l|l|l|l|l|}
\hline & \multicolumn{3}{|c|}{$\begin{array}{c}\text { \% Población provincial en la } \\
\text { capital }\end{array}$} & \multicolumn{3}{|c|}{ Capital/segunda ciudad } \\
\cline { 2 - 6 } & 1996 & 2003 & 2008 & 1996 & 2003 & 2008 & \\
\hline Almería & 34.1 & 31.3 & 28.1 & 3.6 & 2.9 & 2.3 & El Ejido \\
\hline Cádiz & 13.2 & 11.7 & 10.4 & 0.8 & 0.7 & 0.6 & Jerez \\
\hline Córdoba & 40.2 & 41.1 & 40.7 & 8.7 & 8.2 & 7.8 & Lucena \\
\hline Granada & 30.4 & 28.7 & 26.3 & 4.9 & 4.4 & 4.0 & Motril \\
\hline Huelva & 31.0 & 30.7 & 29.1 & 7.8 & 6.8 & 5.9 & Lepe \\
\hline Jaén & 16.2 & 17.7 & 17.4 & 1.7 & 2.0 & 1.9 & Linares \\
\hline Málaga & 43.9 & 39.8 & 36.3 & 5.5 & 4.7 & 4.3 & Marbella \\
\hline Sevilla & 40.9 & 39.8 & 37.4 & 7.7 & 6.6 & 5.8 & Dos Hermanas \\
\hline
\end{tabular}

Pueden hacerse otras comparaciones para la población residente en municipios con más de 20.000 habitantes, que se acerca a los dos tercios a nivel estatal y Andalucía queda un poco por debajo. En una situación media en la tabla de los porcentajes, inferior a Comunidades con conocidas altas tasas de urbanización, como Madrid, Cataluña, País Vasco o Valencia. Pero, también, los dos archipiélagos y provincias con bastantes núcleos importantes como Murcia (Cartagena, Lorca, Molina de Segura) y Asturias (Gijón y Avilés, además de Oviedo). En cambio, la Meseta (las dos Castillas, y Extremadura), Galicia y Navarra están por debajo del $50 \%$. Los niveles de desarrollo aumentan la urbanización y la posición litoral favorece, por lo general, esa tendencia.

La posición de las ciudades medias en la red urbana la define GANAU, 2003, por los siguientes factores: masa crítica o cantidad de población, posición en el sistema urbano europeo, el proceso de metropolización, la nueva organización autonómica y la situación respecto a las infraestructuras de transporte. Andalucía está en la periferia continental, aunque posee la ventaja de enlazar dos ejes europeos, el mediterráneo y el atlántico, además de su proximidad a África. Los procesos de metropolización son 
fuertes, y no sólo en Sevilla, Cádiz o Málaga-Costa del Sol, y el sistema autonómico consolida el sistema urbano y le da cada vez más entidad, mientras que la red de ciudades medias está bien posicionada en las vías rápidas.

Efectivamente, quedan fuera de ellas y a una cierta distancia las siguientes: de entre las superiores a $20.000 \mathrm{~h}$. en el 2008, Rota, que enlazaría (al igual que Chipiona, próxima a la población citada) con la autovía Jerez-Puerto Real o Jerez-Sanlúcar. En Jaén, Alcalá la Real, y entre ésta y Cabra, Priego de Córdoba. Palma del Río podría unirse por Écija a la vía Córdoba-Sevilla; Morón accedería a la A-92 por Puebla de Cazalla, y La Rinconada se aproximará más a Sevilla con la proyectada SE-40.Una autovía por el Valle del Guadalhorce alinearía Coín, Cártama (enlazada ya con la capital) y los dos Alhaurín con Málaga, pero, quizás la ciudad media más importante al margen, y a distancia, de las vías rápidas es Ronda, cabecera comarcal y ciudad turística, que necesita la construcción de la autovía Sevilla-San Pedro de Alcántara con todas las salvaguardas medioambientales necesarias, ya que la actual carretera circula entre las sierras Bermeja y de las Nieves.

\section{LA IMPORTANCIA DE LAS CIUDADES MEDIAS}

Existe bastante interés por el estudio, la consideración y el fomento de estas poblaciones en Andalucía. Algunas muestras de este interés son las siguientes: Jornadas sobre ciudades medias (Consejería de Obras Públicas y Transporte, 1992), Tesis de Valenzuela (2000), artículo de Escalera (2006), Fundación Ciudades Medias Centro de Andalucía en Ayuntamiento de Loja, II Congreso andaluz de ciudades medias en esa población granadina (octubre del 2008). También, están los planteamientos de la administración autonómica, que señalan pautas y plantean normas. En general, hay bastantes escritos sobre este particular, de los que nos referiremos a algunos citados en la Bibliografía, avanzando que, según MALLARACH y VILAGRASA, 2002, sólo recientemente se atienden a ciudades medias fuera de áreas metropolitanas, que, en nuestra opinión, son las más importantes en relación a la articulación del territorio.

Así, VILAGRASA, 2004, pone de manifiesto las ventajas de las ciudades medias frente a las grandes: más calidad de vida, menos conflicto social, mayor capacidad de autoidentificación. Pero también señala puntos débiles: excentricidad 
territorial, escasez demográfica, limitada capacidad de innovación, estructura social inmovilista y otras; e indica la competencia entre ellas para conseguir nuevos usos e inversiones (p. 2). En este sentido, GANAU, 2003, detecta un descenso de la dependencia de las ciudades medias, respecto a las grandes, y el aumento de las conexiones horizontales entre ciudades de parecido tamaño.

Las consecuencias de la introducción o desarrollo del calificativo de ciudades intermedias en la urbanización mundial (por ejemplo, LLOP, 1999) potencian el intercambio y la cooperación a escalas amplias como centros más sostenibles y se señalan sus ventajas (sostenibilidad, gobernabilidad, posibilidad de diseños ecológicos...), se plantean estrategias y se prepara una encuesta, sobre la que se comentan unos primeros resultados. Y acaba la publicación con unas consideraciones (como el grado de diversidad del conjunto o la idoneidad de la escala para ensayar propuestas) y unas declaraciones.

BELLET y LLOP, 2004, abundan en el calificativo de ciudades intermedias, destacando las funciones territoriales y la relación con otras urbes de diferentes tamaños, como nodos con características de mediación en diversos aspectos: flujos (información, bienes, administración, innovación...) rural/urbano, espacios locales/ regionales, entre pequeños y grandes, entre territorios próximos o lejanos, vínculos con el hinterland (funcional, social, cultural), etc. Tal intermediación requiere una considerable red de infraestructuras y se expresa, según los dos autores citados, en tres niveles: político administrativo y desarrollo de democracias más participativas, servicios personales y para las empresas, así como la distribución e intercambio como ciudades-mercado, que han sido por lo general. Ambos autores abundan en las ventajas de estos núcleos: calidad de vida, más seguridad ciudadana y tiempo libre, mejores ratios de equipamientos, menos contaminación y congestión de tráfico, mayor relación con el espacio público, más facilidad de crear identidades y de participación, tramas urbanas más compactas, riqueza monumental... Pero también citan inconvenientes. Finalmente, plantean unos retos para estas ciudades: su papel en la globalización, relación con los procesos de metropolización y de dispersión de la población, colaboración con el desarrollo local o cómo pueden ser influidas por las nuevas tecnologías o espacios virtuales.

Los desplazamientos desde el campo hacen aconsejar a DE ESTEBAN, 1989, una buena política de promoción de ciudades medias, potenciando los 
servicios y equipamientos para, además de crear puestos de trabajo y atender las necesidades de sus habitantes, ofrecer a su área de influencia más calidad de vida y fijar la población rural, a la vez que contribuye a disminuir la emigración a las grandes aglomeraciones. Así, las funciones que deben cumplir las ciudades medias son: crear empleo para la población rural, en la industria y, sobre todo, los servicios; ofrecer viviendas y equipamientos colectivos; satisfacer la demanda de educación, servicios culturales, sociales, etc. (también de ocio y cultura, podría añadirse); facilitar eficientes medios de transporte y comunicaciones y fomentar el desarrollo endógeno (DE ESTEBAN, 1989, p. 9).

Evidentemente, muchas de esas características son aplicables al caso andaluz, del que, por cierto, varios autores advierten que las agrociudades, hecho específico de esta tierra, sobre todo en la denominación, tienen cada vez más funciones propiamente urbanas y menos población agraria. La CONSEJERÍA DE OBRAS PÚBLICAS Y TRANSPORTES, 2006, considera el sistema de ciudades como estrategia de desarrollo territorial, junto con el Sistema de Articulación Regional (transportes, telecomunicaciones, energía...) y el Sistema Regional de Protección del Territorio (prevención, riesgos, patrimonio). Se recoge, así mismo, un Programa Andaluz de Ciudades con carácter plurianual, redactado por una comisión interdepartamental con la intervención de varias consejerías, que pretende una estrategia para cada elemento de la red urbana.

Dentro del Sistema de ciudades, y después de las aglomeraciones, hay una sección sobre ciudades medias, a las que se les reconoce una función especial en la articulación del territorio (entre las grandes aglomeraciones y las zonas rurales), un rico patrimonio urbano, que debe preservarse (tanto por lo que representa de urbe mediterránea compacta, como por la riqueza monumental y cultural) y una buena distribución territorial y variedad de funciones. Y en este aspecto se distinguen las integradas en áreas metropolitanas, las litorales, interiores (muchas herederas de la agrociudades) y ciudades medias en áreas de montaña. Y se prevé un buen futuro, al beneficiarse de la economía de escala por su funcionamiento en red, que aumenten la cooperación y el mercado, debiéndose tender a favorecer los sistemas productivos locales.

Se destaca la Costa del Sol, de dimensión internacional, pero también la zona central (Subbético, Intrabética, Campiñas, etc.) y se contemplan infraestructuras 
rápidas que potencien esa red: Úbeda-Baeza, Linares-Albacete, Granada-CórdobaBadajoz-Lisboa. Así mismo, el norte y oeste de la provincia de Jaén y el Valle del Almanzora, para integrar las redes de ciudades medias en los ejes de articulación de Andalucía. De esta forma, el Programa Andaluz de Ciudades contemplará para las urbes medias la plasmación de objetivos mediante "la planificación territorial, la coordinación de acciones en materia de equipamientos y servicios públicos de carácter supramunicipal, así como para la dotación de suelos para actividades productivas" (p.44). De esta manera, se abren en el texto los siguientes apartados: planes de ordenación del territorio, localización de equipamientos y servicios especializados, públicos de carácter supramunicipal, funciones de las redes de ciudades medias en los ejes de articulación regional y redes de ciudades medias y cooperación.

\section{EL ESTADO DE LA CUESTIÓN EN LÍMITES Y CLASIFICACIONES}

Bastantes autores señalan la variedad de límites para definir el hecho urbano y las ciudades medias según las escalas y dentro de una misma. Así, el Banco Mundial incluye hasta un millón de habitantes y, para la Unión Europea, oscila entre 50.000 y 500.000, y en el Estado Español también existe heterogeneidad, "aceptándose, siempre, un cierto grado de arbitrariedad en la definición" (GANAU y VILAGRASA, 2003). Para el INE, el umbral rural-urbano es de 10.000 habitantes y en 1981 el MOPU lo establecía en 5.000, lo que puede considerarse demasiado bajo en general y, desde luego para Andalucía, donde, como veremos, las agrociudades suelen ser mayores. Vamos a intentar una puesta a punto de la cuestión apelando a una serie bibliográfica, quizás no exhaustiva, pero sí significativa, obviando los estudios sobre ciudades andaluzas concretas, que son bastantes, y considerando sobre todo el caso andaluz.

Existen algunos trabajos a nivel estatal desde los años sesenta del siglo XX, como el Plan CCB de Cáritas, 1965 (que hace una relación de núcleos en diez tipos según el medio rural/urbano y la actividad predominante), y a principios de los setenta hay una serie de informes de comisiones provinciales e interministeriales sobre cabeceras comarcales. En 1983 la Consejería de Política Territorial de la Junta de Andalucía elabora una propuesta de Comarcalización con 122 ámbitos y 127 cabeceras (pues hay algunas dobles) muy en relación con análisis de llamadas 
telefónicas y accesibilidad, pero no llegó a estar vigente. Para más información y valoración de esta propuesta, puede verse CANO, 1987, tomo VII, cap. 1.

Y la misma Consejería publica en 1986 dos volúmenes sobre el Sistema de ciudades, dirigido por FERIA, que distingue cuatro niveles: Sevilla, capital regional, nueve centros de segundo orden o subregionales (las siete capitales, más Jerez y Algeciras), 18 centros intermedios con clara centralidad y fuerte potencial funcional (excepto Pozoblanco y Peñarroya, que son de cuarto orden). Los 28 centros de las tres primeras categorías aparecen en los grandes ejes urbanos de Andalucía: valle del Guadalquivir, Subbético, Depresión Intrabética y Costa, quedando fuera las Sierras y parte de las provincias de Almería y Huelva, donde dominan núcleos con débil potencial y escasa centralidad divididos en dos grupos. En total, suman 132 centros urbanos en 122 ámbitos, porque se trata de espacios comarcales y no se incluyen límites poblacionales ni las periferias metropolitanas, entonces, desde luego, bastante menos desarrolladas que ahora. Antes, 1982, se publica el libro de PEZZI sobre comarcalización de Andalucía, cuyas cabeceras interesa para lo que tratamos aquí.

En 1987 CANO (Geografía de Andalucía, en ocho tomos, 1987-90) presenta una jerarquización de los núcleos andaluces como un parámetro para el análisis comarcal y para añadir a lo meramente demográfico otras variables. Fueron concretamente 43 distribuidas en ocho grupos: economía (entidades financieras, consumo de energía, índices turísticos, industria, etc.), comercio, servicios públicos (educativos, sanitarios, judiciales y administrativos), población activa en servicios, transportes y comunicaciones, destino de líneas de autobuses, número de enlaces (ligazones de cada centro en flujos de distinto tipo) y distancia entre ellos (Véase tomo 8, pp. 186-204).

Tras la elaboración, el resultado fue una relación de núcleos por rangos desde el 3 de Sevilla al 147 de Puebla de Cazalla, comprendiendo 141 municipios, que se comparan con el Sistema de Ciudades de 1986 y que no siempre siguen el orden demográfico, sobre todo en los rangos más bajos. Por ejemplo, Úbeda, en el lugar 30 por población, ostentaba el 15 por su importancia como cabecera comarcal de un ámbito que va más allá de las Lomas para introducirse en parte del Condado, Cazorla y Segura. Y algo similar ocurre con otros centros, como Baza (52 y 30), Ronda (26 y 18) o Antequera (23 y 16). Por el contrario, municipios próximos a otras capitales se incluyen en ellas como barrios o ciudades dormitorio; por ejemplo, Dos Hermanas 
en Sevilla o San Fernando en la Bahía de Cádiz, ostentando mejores posiciones demográficas que en la relación obtenida según las centralidades: 13 y 23 , y 11 y 20 , respectivamente.

Resultan seis grupos separados por saltos de rango e integran todos los mayores de 10.000 (el último, Puebla de Cazalla, como dijimos), según datos de 1986, que son 117. Más 24 menores de $10.000 \mathrm{~h}$., que entran en la lista por su rango, de acuerdo con las variables señaladas, antes de ese lugar 141 (rango 147). Después de Sevilla, el grupo segundo comprende las otras siete capitales, más Jerez y Algeciras, y el grupo tercero abarca 20 núcleos, algunos con extensas áreas de influencia: Motril, Baza, Guadix, Linares, Marbella, Vélez-Málaga, Antequera, Ronda, Écija, Utrera, Morón, Lucena, Linares y Úbeda. Mientras, los otros seis están demasiado cerca de capitales o centros importantes como para organizar espacios propios: Dos Hermanas, Alcalá de Guadaíra, El puerto, San Fernando, La Línea y Fuengirola. Este tipo de centros que interesan también porque, cuando menos, sirven a su población, disminuyen en los grupos siguientes.

La jerarquización señalada sirve de base para una aproximación a la comarcalización (CANO: Geografía de Andalucía, tomo ocho, pp. 205-259). Se utilizan distintas variables, pero principalmente la funcional y se manejan elementos polarizantes en diferentes cuadros, comparándose con las divisiones de la Junta de Andalucía de 1983, cuyos detalles interesan menos ahora a efectos de límites y clasificaciones urbanas.

CUADRO 2. Resumen de la clasificación de Cano, 1987

\begin{tabular}{|c|c|c|c|}
\hline & & \multicolumn{3}{|c|}{ Orden } \\
\hline 1 & 1 & 1 & 1 \\
\hline $\mathbf{2}$ & 9 & $2-10$ & Población, 1986 \\
\hline $\mathbf{3}$ & 20 & $11-30$ & $4-10$ \\
\hline $\mathbf{4}$ & 22 & $31-52$ & $16-52$ \\
\hline $\mathbf{5}$ & 32 & $53-84$ & $17-37$ \\
\hline $\mathbf{6}$ & 57 & $85-141$ & $25-174$ \\
\hline & 141 & $1-141$ & $104-114$ \\
\hline
\end{tabular}


En 1987 DE ESTEBAN delimita a la ciudad más como un concepto sociológico que administrativo y advierte de la variedad de intervalos poblacionales según continentes y países. De esta manera, en Europa Occidental la urbe media está entre 20.000 y 200.000 habitantes, Francia sólo llega a los 100.000, el INE establece lo urbano con más de $10.000 \mathrm{~h}$. y señala para España: áreas metropolitanas, capitales de provincia, ciudades medias, núcleo urbanos de menos entidad y áreas rurales.

En 1990 la Consejería de Obras Públicas y Transportes organizó unas Jornadas sobre ciudades medias, que dio lugar a una publicación al año siguiente, que, consultada, proporciona información acerca de lo que estamos tratando. Así, BRAVO y PAREJO abordan la tipología de Ciudades Medias según la oferta de servicios públicos especializados y señalan los umbrales siguientes: en aglomeraciones urbanas y áreas metropolitanas, más de 20.000 h.; las áreas turísticas dinámicas tienen núcleos normalmente con más de 15.000 , pero algunas que apenas sobrepasan 10.000, llegan a 100.000 en verano; ámbitos rurales en las Campiñas interiores andaluzas más de 10.000 , y normalmente entre 25.000 y 50.000 h.; y, finalmente, ámbitos rurales de baja densidad con núcleos 5.000-10.000 y con poblaciones totales de ámbitos no superiores a 25.000 habitantes.

CASASSAS cree en una nueva concepción de la ciudad que desborda límites administrativos y se relaciona más con el territorio: ciudad-región, ciudad-comarca o ciudad-aglomeración menor. LÓPEZ CHACÓN, también en ese Congreso de 1990, delimita las urbes medias entre 20.000 y 90.000 habitantes, "que muestran un ritmo notable de crecimiento demográfico, salvo las que forman parte de áreas metropolitanas y cuyo desarrollo responden a un manifiesto proceso de difusión (Alcalá de Guadaíra, Camas y Dos Hermanas en Sevilla; San Fernando y el Puerto de Santa María en Cádiz)".

MONTEAGUDO menciona el intervalo 20.000-100.000, pero utiliza los centros básicos del Sistema de Ciudades para la Costa de Huelva. Y ZOIDO maneja los mismos umbrales para urbes medias, aunque añade que eso hay que completarlo con observaciones de tipo funcional, porque algunas están en aglomeraciones y son solo residenciales. Recuerda, por otra parte, que "el ordenamiento legal vigente... y los tratamientos estadísticos utilizan los límites cuantitativos de 5.000, 20.000, 25.000 y 50.000 habitantes por municipio con diversa finalidad, y sin utilizar la expresión ciudad media, pero marcando funcionalmente quizás en mayor medida los límites de este concepto en relación a las cifras centrales". 
En 1992 FERIA, pionero de estos estudios, como dijimos (1986, con ampliación en 1987), perfecciona la clasificación con especial atención a la escala intermedia, y los objetivos de profundización en el conocimiento de los sistemas de asentamiento, las estructuras y formas de cada categoría y sus explicaciones. Diferencia cuatro grupos: aglomeraciones urbanas (seis: áreas de Sevilla, Málaga, Vega de Granada, Huelva, Bahía de Cádiz-Jerez, y Bahía de Algeciras) y ámbitos con organización centralizada, que comprenden más del $80 \%$ de la población, espacios con organización no centralizada y territorios desarticulados.

LÓPEZ ONTIVEROS, 1994, opina que, más allá de la dicotomía rural/urbano y los límites por habitantes, hay áreas culturales con grandes poblaciones agrarias, como Sicilia o Andalucía. Para la primera rigen los límites entre 3.000 y $30.000 \mathrm{~h}$, según distintos autores y zonas, y para la segunda el mismo intervalo (GIMORE, 1980) o 900-22.000 en la campiña de Córdoba (DRIESSEN, 1981). Añade las siguientes características para las agrociudades andaluzas: población concentrada generalmente en el núcleo mayor, predominio del sector agrario, extensos y feraces términos municipales y el significado del sector urbano.

SALOM, 1995, sitúa el umbral de ciudades medias entre 50.000 y $200.000 \mathrm{~h}$. y compara sobre todo la situación de Cataluña y País Valenciano. OCAÑA, 1998, analiza el modelo de áreas sociales de distintas ciudades, sobre todo Málaga, y clasifica los municipios en seis intervalos entre menos de 2.500 y más de 100.000 habitantes. VILAGRASA, 1999, considera ciudades medias entre 20.000-200.000, que no formen parte de áreas metropolitanas, pero hay distintas situaciones poco generalizables y más cualitativas (agrociudades andaluzas, ciudades pequeñas del eje navarro-riojano, núcleos pequeños y medios catalanes...). Sobre aglomeraciones, distingue: ciudades en el entorno de metrópolis consolidadas, como Madrid, Barcelona, Bilbao, Sevilla y Málaga (se supone que también Valencia); en zonas más o menos consolidadas y de carácter lineal, como el eje litoral gallego o Alicante-Elche-Murcia (o también Costa del Sol); áreas urbanas principales o ciudades grandes, como Valladolid, Albacete 0 Jaén.

En 1999 se publicó en Lleida (LLOP, director) un libro sobre Ciudades intermedias y urbanización global, producto de la colaboración de varias instituciones, entre ellas, la UNESCO, que venía interesándose con anterioridad por este tema. A fin de considerar una escala internacional, colocan los límites entre 20.000 y 2.000 .000 
de habitantes, añadiendo otras características, como que no se trate de capitales estatales, pero configuren un área metropolitana grande en su región y posean cierta influencia territorial. Plantean una encuesta con bastantes preguntas, de las que analizan unos primeros resultados.

VALENZUELA, 2000, sitúa las ciudades medias entre 15.000 y $50.000 \mathrm{~h}$. estudiando en sus tesis doctoral ocho ciudades medias, realmente significativas, pues son cabeceras comarcales bien distribuidas por el territorio, destacando la Depresión Intrabética: Antequera, Baza, Guadix, Loja, Montilla, Priego, Ronda y Úbeda.

Desde 1997, el Grupo de Investigación Estudios Geográficos Andaluces, dirigido por G. CANO y R. JORDÁ, realizó un amplio trabajo sobre las Comarcas Andaluzas, publicado en el 2002, donde se aplicaron diversas variables. Interesa en particular algo importante, que estaba sin hacer, cual son las áreas de influencia de los centros comarcales o metropolitanos. Se diseñó, distribuyó y se elaboraron los resultados de una encuesta en la que se preguntaba en los distintos municipios de Andalucía dónde se adquirían determinados bienes y servicios o se realizaban diversas gestiones. Así, resultó un complicado mapa de áreas funcionales ( $p .18$ del libro citado), que fue la base de la comarcalización realizada después y, a los efectos que ahora nos ocupan, una fundamental aportación para la clasificación urbana de Andalucía.

Tras una compleja elaboración, se define la población desplazada ponderada (según el peso relativo de cada servicio en Andalucía) o PDP, como algo más aquilatado que la población potencialmente atraída (Véase CANO, 2000, tomo 5 , pp. 25-46). Así, hay un elemento importante para la jerarquización y clasificación, aunque no fue el único. Se utilizaron la población de 1986 y 1996, el orden obtenido en 1987 y resumido aquí en el cuadro 2 , el lugar que ocupa cada centro en la citada PDP, el número de enlaces con otros núcleos y la mediana de variables. Todo el proceso, características, método, etc., puede constatarse en la citada publicación y lo que interesa ahora es la clasificación, cuya cartografía aparece en la página 44 de la misma:

En primer lugar, a) capitales de provincia; b) centros con más de $50.000 \mathrm{~h}$., distinguiendo si son cabeceras de ámbitos o forman parte de aglomeraciones y áreas metropolitanas; c) núcleos con más de 20.000 , estableciéndose la misma distinción 
más un tercer bloque con municipios dudosos (Martos en relación con Jaén, Adra/El Ejido, etc.). Hasta aquí se distinguen grupos de tamaño y su capacidad de organizar espacios, según la comarcalización realizada, muy basada, como dijimos, en el mapa de áreas funcionales, a la vez que las variables citadas caracterizan los tipos y cada núcleo.

Después vienen dos apartados en los que la clasificación establecida sirve no sólo para caracterizar las agregaciones a), b) y c), sino también a efectos de clasificar. Porque se localizan las cabeceras comarcales de entre 10.000 y 20.000 (grupo d), pero con dos subapartados, según el lugar que ocupa en la PDP (población potencialmente desplazada y ponderada), concretamente hasta el $n^{0} 53$ (Huércal Overa en Almería, Pozoblanco y Peñarroya en Córdoba; Lora del Río, Osuna, Estepa y Sanlúcar la Mayor en Sevilla; Valverde del Camino y Lepe -ahora ya tiene más de 20.000- en Huelva; Coín en Málaga) y de éste al 100 (Villacarrillo en Jaén, Ayamonte en Huelva y Ubrique en Cádiz).

Pero aún quedaban posibles cabeceras de ámbito, según la comarcalización elaborada, por debajo de los 10.000 habitantes (zonas de sierras y desarticuladas), que lógicamente incluimos, separando también en dos partes según la lista de la PDP. Primero, las que llegan hasta el número 53 (Vera en Almería; Órgiva en Granada; Aracena, Minas de Riotinto y la Palma del Condado en Huelva) y las que van de ese límite (los umbrales están justificados en la publicación citada) al 100 (Vélez Rubio, Albox y Olula del Río en Almería; Huéscar en Granada; Huelma en Jaén; Cazalla y Costantina en Sevilla; Puebla de Guzmán en Huelva). Es decir, una clasificación que va más allá del tamaño poblacional para utilizar otras muchas variables y, sobre todo, considerar el territorio, señalando los núcleos que no organizan espacios propios y aquéllos que tienen bastante 0 cierta centralidad, aunque no lleguen a los 10.000 habitantes.

Continuando el repaso de aportaciones (sobre todo de Andalucía, aunque no exclusivamente) por orden cronológico, MALLARACH, 2002, estudia procesos de desconcentración de 37 ciudades medias con límites entre 50.000 y 300.000 habitantes, excluyendo las de entornos metropolitanos y las comprendidas en esos umbrales pero que centran áreas de más de 400.000. GANAU y VILAGRASA, 2003, adoptan los siguientes criterios para urbes medias: entre 50.000 y 300.000 habitantes, capitales de provincia menores de 50.000 y excluyen las ciudades que forman parte de Áreas Metropolitanas y las que configuran zonas propias mayores 
de 400.000 h. Estos límites comprenden en Andalucía sólo seis urbes: Almería, Jaén, Huelva, Algeciras, Linares y Motril con datos del 2001. A ellas se añadirían en 2008 las siguientes: El Ejido, Roquetas de Mar, Sanlúcar de Barrameda, Vélez Málaga y Marbella. Sin contar Fuengirola y Estepona como núcleos en el área de la Costa del Sol y otros en áreas de Sevilla, Málaga o Bahía de Cádiz.

BELLET y LLOP, 2004, estudian 96 ciudades intermedias del proyecto CIMES (LLOP, 1999) entre los intervalos de menos de 140.000 h. y más de 640.000 con una media del conjunto próxima a 385.000 habitantes. $Y$ consideran que el adjetivo intermedia, en lugar de media, añade una menor dependencia del tamaño y alude más al medio y su articulación con el resto del sistema, incorporando dinamismo e interactividad. El Atlas Estadístico de las Áreas Urbanas en España, 2005, citado por MÉNDEZ, 2007, clasifica de la siguiente manera:

- Grandes áreas urbanas con un núcleo central por encima de los 50.000 h. y otros contiguos, siempre que reúnan ciertos requisitos, siendo en Andalucía: Sevilla (24 municipios), Málaga (8), Bahía de Cádiz (6), Granada (30), Córdoba (1), Bahía de Algeciras (4), Almería (5), Costa del Sol (3), Huelva (3), Jaén (4), Vélez-Málaga (3), Sanlúcar de Barraneda (1), El Ejido (1), Linares (1) y Motril (1). Aunque, obviamente no todas son grandes áreas urbanas y veremos cómo, sobre todo las 5 últimas, son más bien ciudades medias.

- Pequeñas áreas urbanas con municipio central entre 10 y 50.000 habitantes 0 , incluso, 5.000 , si su potencial de acogida supera los 15.000. Con este criterio resultan 65 áreas andaluzas de un solo municipio.

CARAVACA, 2005, denomina ciudades pequeñas y medianas a las 131 con más de $10.000 \mathrm{~h}$. y clasifica en seis tipos a las 49 seleccionadas según su capacidad innovadora (superar el valor medio andaluz, al menos, en 4 de los indicadores utilizados). También en el 2005, OCAÑA clasifica el sistema urbano andaluz de la siguiente manera: primero, las capitales provinciales más Algeciras y Jerez, y, después, pone el límite en los $10.000 \mathrm{~h}$. con tres categorías: ciudades medias con más de 50.000; ciudades medias 30-50.000; ciudades medias 20-30.000; pequeñas ciudades 10-20.000, desestimando aquéllas con menos de 15.000 y cuya ocupación agraria sea, a la vez, mayor del $30 \%$. Aplicando dinámicas demográficas, saldos, edad, instrucción, rama actividad, etc., obtiene la siguiente distribución: 

a) Ciudades medias en entornos metropolitanos
b) Ciudades medias turísticas o espacio litoral
c) Ciudades medias en espacio rural

En el 2006 CANO vuelve a analizar límites, poniendo en duda los 10.000 habitantes, que, manejados mucho tiempo para ciudades medias, son hoy pocos para una urbe con suficientes funciones y atracción de un entorno. De esta manera, que utiliza de forma convencional y comparativa el límite de los 20.000 habitantes y establece en un análisis minucioso la correspondencia para mediados del XIX, que serían los 10.000 e, incluso, algunos núcleos de 5.000 h. DÍAZ QUIDIELLO, 2006, recuerda diversidades de límites, continentales y de países, y señala para Andalucía como ciudades medias las ubicadas entre las diez primeras y las propiamente rurales, generalmente entre 20.000 y 100.000 h,, aunque puedan sobrepasarse ambos límites, y haya que considerar el grado de centralidad.

Ese mismo año 2006 la CONSEJERÍA DE OBRAS PÚBLICAS Y TRANSPORTES publica el POTA, donde se clasifican los municipios en tres grupos:

1. Centros regionales, que son los ámbitos de las capitales provinciales más el Campo de Gibraltar, uniéndose la Bahía de Cádiz con Jerez.

2. Redes de ciudades medias, exceptuando las incluidas en las áreas anteriores y distinguiendo dos subgrupos, ciudades medias 1 y ciudades medias 2, más por la centralidad que por el tamaño, aunque hay cosas discutibles. Así, Antequera aparece en el primer grupo y Ronda en el segundo cuando el área de influencia de cada una no lo decide así.

3. Asentamiento de áreas rurales.

Otra cosa son las redes marcadas en la cartografía, que en algunos casos parecen más bien proyectos de futuro y señalan las grandes estructuras urbanas andaluzas con desarrollo en las aglomeraciones citadas: Valle del Guadalquivir (con la prolongación hasta Ayamonte por la Autovía de los Descubrimientos), Subbético (de Jaén, Córdoba y Sevilla, más conectado con el Valle, vía Campiñas, que con la Depresión), Surco Intrabético y Costa. Se añaden algunas áreas como el Valle del Almanzora o Ronda-Arcos. 
MÉNDEZ, 2007, de acuerdo con los responsables del Instituto de Estadística de Andalucía, considera urbanos a los superiores a $10.000 \mathrm{~h}$. y, como lo manifiesta dentro del apartado de ciudades intermedias, se supone que ese es el límite. Excluyen a las ocho capitales más Jerez y Algeciras (POTA, 2006) y así resultan 154 municipios, ya que "lo más frecuente en los estudios comparativos realizados hasta el momento a escala urbana es la utilización del municipio como unidad de base, aunque sea cuestionable en algunos casos su correspondencia con el concepto de ciudad". Y añade que ahora es frecuente lo contrario: que lo urbano desborde los límites administrativos. Recientemente, 2008, RODRÍGUEZ MARTíNEZ, además de estudiar los cambios en la estructura de la población activa 1950-2001, sitúa a lo que ha dado en llamarse ciudades medias entre 10.000 y 100.000 habitantes, y hace una clasificación del poblamiento en general, desde menos de 100 habitantes hasta más de 500.000. JORDÁ y GONZÁLEZ, 2009, colocan los limites 10.000-100.000 h. y diferencian grandes urbes de intermedias y pequeñas en distintos parámetros (venta o compra de tecnología, inversiones en I+D, etc.).

En resumen, el límite urbano de los 10.000 habitantes está bastante aceptado, pero en lo referido a ciudades medias hay variedad, confluyendo distintos autores en el umbral mínimo de 20.000 (Cano, 1987 y 2006; López Chacón, 1990; Salom, 1995; Llop, 1999; Villagrasa, 1999; Monteagudo, 1990; Ocaña, 2005). Sin embargo, el tope máximo no es uniforme $(50.000,90.000,100.000,200.000$ y hasta dos millones de habitantes), si bien confluyen cuatro en los 100.000 (Cano, Monteagudo, Ocaña y Jordá-Glez Relaño). Otros cuatro colocan el límite inferior de ciudades medias en 10.000 h. (Atlas Estadístico, 2005; Caravaca, 2005; Rodríguez, 2008 y Jordá-Glez. Relaño) con cifras distintas en la parte superior (50,300 y 100 mil, repectivamente). Y, por último, Valenzuela, 2000, las sitúa entre 15.000 y 50.000 h., mientras Mallarach y Vilagrasa, 1999, lo hacen entre 50.000 y 300.000 h., a la vez que la ciudad intermedia de Bellet y Llop, 2004, estaría en una media de casi 400.000 habitantes.

Para cinco de los autores consultados habría varios grupos dentro de las ciudades medias: Bravo y Parejo, 1990; López Ontiveros, 1994; Cano, 2000; Ganau, 2003, y Ocaña, 2005. Y aún se distinguen algunos más para los que los límites no son, o no son sólo, numéricos (Feria, 1986 y 1992; Cano, 1987 y 2000; Esteban, 1987; Cassasas, 1990; Ocaña, 1998; Llop, 1999; Vilagrasa, 1999; Mallarach y Vilagrasa, 
1999; Bellet y Llop, 2004, y el POTA, 2006), separando en algunos casos los centros cabeceras comarcales de los incluidos en aglomeraciones.

\section{UNA NUEVA PROPUESTA}

Vamos a mantener la diferenciación realizada desde 1987 entre núcleos con centralidad y los que se integran en áreas metropolitanas y aglomeraciones, añadiendo los lugares de comarcas polinucleares y otros que no responden a ningunos de los tres apartados anteriores. El planteamiento, pues, es fundamentalmente territorial, utilizando las 62 comarcas que planteamos en el 2002, de donde se extraen las cabeceras, contándolas todas, incluso las menores de 5.000 habitantes en zonas desarticuladas. Ahora bien, esos cuatro tipos enumerados los englobamos en varios grupos, según el tamaño, con lo que se posibilitan cuantificaciones desagregadas que pueden unirse en cualquier momento. $Y$, aunque el principal objetivo son las ciudades medias, queremos plantearlo dentro de todo el sistema del poblamiento andaluz, como se aprecia en el cuadro adjunto, del que hacemos ahora algunos comentarios de tipo general. Antes, advertir que dentro de cada grupo y subgrupo existen diferencias según la localización (costa, interior, campiña, montaña, ejes...), como veremos después.

El $30 \%$ de la población andaluza reside en las ocho capitales, y, acumulando, la mitad, en ciudades con más de 50.000 habitantes, subiendo el porcentaje a los dos tercios (66.84) si bajamos el límite a los 20.000 h. Y, si entre esta cifra y los 100.000 se consideran ciudades medias, éstas alojarían al $30 \%$ de los andaluces. Es una primera aproximación a la importancia demográfica de nuestro sistema de ciudades, que supone nada menos que el $80 \%$ de la población (79.48), si ponemos el umbral de lo urbano en los $10.000 \mathrm{~h}$. 
CUADRO 3. LÍMITES URBANOS, 2007

\begin{tabular}{|c|c|c|c|c|}
\hline & \multicolumn{2}{|c|}{ MUNICIPIOS } & \multicolumn{2}{|c|}{ POBLACIÓN 2007} \\
\hline & $\mathbf{N}^{0}$ & $\%$ & $\mathbf{N}^{0}$ & $\%$ \\
\hline 1.- CAPITALES DE PROVINCIAS & 8 & 1,04 & 2.397 .973 & 29,75 \\
\hline 2.- MÁS DE $100.000 \mathrm{H}$. & 4 & 0,52 & 560.685 & 6,96 \\
\hline $\begin{array}{l}\text { 2.1.- Centros comarcales } \\
\text { Algeciras (CA), Jerez (CA), Marbella (MA) }\end{array}$ & 3 & 0,39 & 443.121 & 5,50 \\
\hline $\begin{array}{l}\text { 2.2.- En Áreas Metropolitanas o Aglomeraciones } \\
\text { Urbanas } \\
\text { Dos Hermanas (SE) }\end{array}$ & 1 & 0,13 & 117.564 & 1,46 \\
\hline 3.- $50.001-100.000 \mathrm{H}$ & 16 & 2,08 & 1.072 .853 & 13,31 \\
\hline 3.1.- Centros comarcales & 6 & 0,78 & 380.575 & 4,72 \\
\hline $\begin{array}{l}\text { 3.2.- En Áreas Metropolitanas o Aglomeraciones } \\
\text { Urbanas }\end{array}$ & 7 & 0,91 & 496.383 & 6,16 \\
\hline 3.3.- Polinucleares & 3 & 0,39 & 195.895 & 2,43 \\
\hline 3.4.- Otros & & & & \\
\hline 4.- $20.001-50.000 \mathrm{H}$ & 49 & 6,37 & 1.354 .848 & 16,82 \\
\hline 4.1.- Centros comarcales & 15 & 1,95 & 429.327 & 5,33 \\
\hline $\begin{array}{l}\text { 4.2.- En Áreas Metropolitanas o Aglomeraciones } \\
\text { Urbanas }\end{array}$ & 13 & 1,69 & 344.893 & 4,28 \\
\hline 4.3.- Polinucleares & 15 & 1,95 & 392.305 & 4,87 \\
\hline 4.4.- Otros & 6 & 0,78 & 188.323 & 2,34 \\
\hline 5.- $10.001-20.000 \mathrm{H}$ & 73 & 9,49 & 1.018 .776 & 12,64 \\
\hline 5.1.- Centros comarcales & 4 & 0,52 & 61.040 & 0,76 \\
\hline $\begin{array}{l}\text { 5.2.- En Áreas Metropolitanas o Aglomeraciones } \\
\text { Urbanas }\end{array}$ & 24 & 3,12 & 333.944 & 4,14 \\
\hline 5.3.- Polinucleares & 15 & 1,95 & 217.548 & 2,70 \\
\hline 5.4.- Otros & 30 & 3,90 & 406.244 & 5,04 \\
\hline $6 .-5.001-10.000 \mathrm{H}$ & 107 & 13,78 & 722.395 & 8,96 \\
\hline 6.1.- Centros comarcales & 19 & 2,47 & 125.791 & 1,56 \\
\hline 6.2.- Resto & 88 & 11,44 & 603.751 & 7,49 \\
\hline $\begin{array}{l}\text { 7.- OTROS CENTROS COMARCALES (Menos de } \\
5.000 \mathrm{~h} \text { ) }\end{array}$ & 9 & 1,20 & 20.350 & 0.25 \\
\hline 8.- RESTO (Inferior a $5.000 \mathrm{~h}$, menos el grupo 7) & 503 & 65,41 & 904.354 & 11,22 \\
\hline 9.- TOTAL ANDALUCÍA & 769 & 100,00 & 8.059 .411 & 100,00 \\
\hline
\end{tabular}


藏事

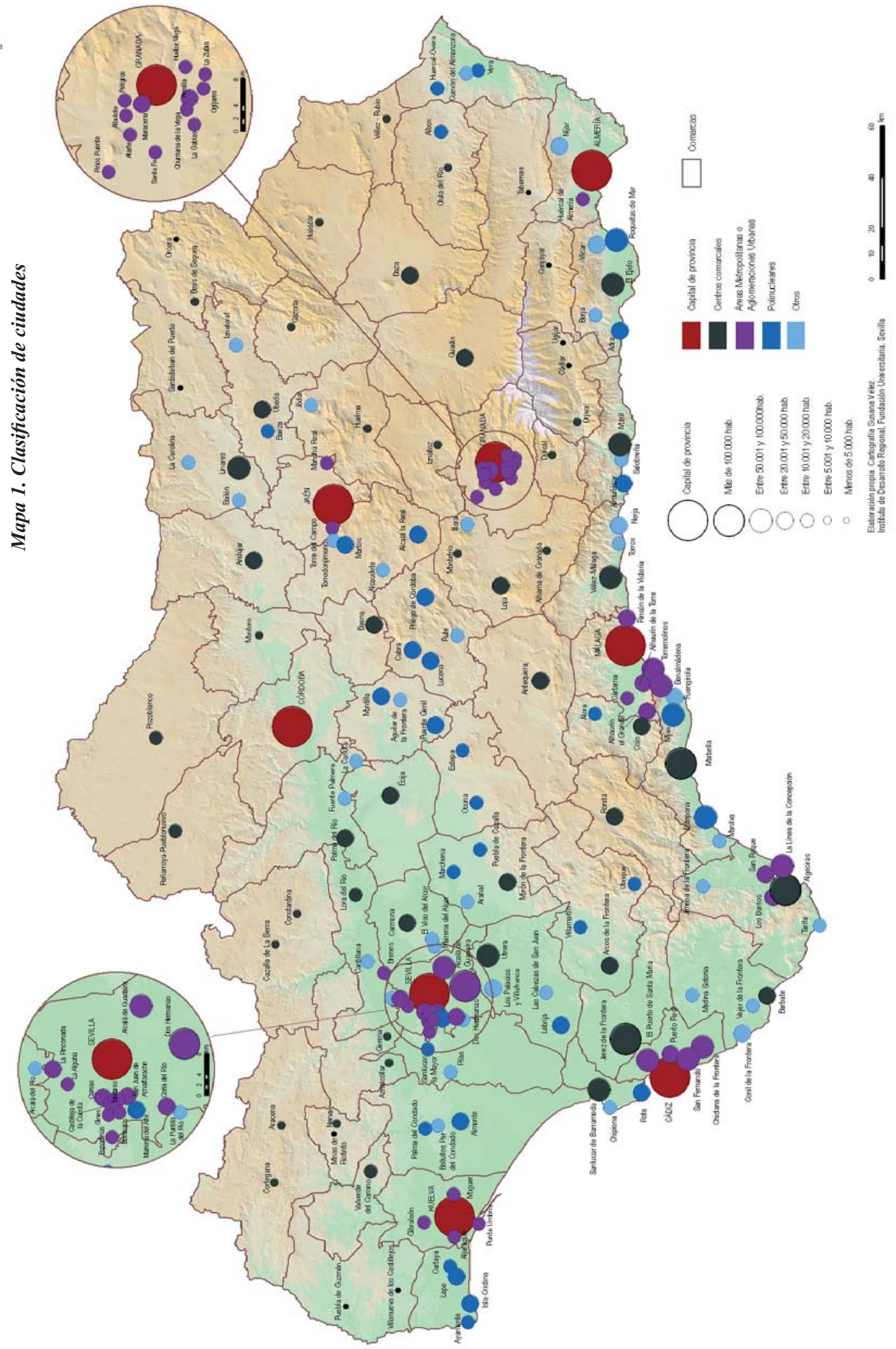

Las ilustraciones que aperecen en esta publicación en blanco y negro (para ahorrar costes de impresión) pueden verse en color en

http://www.institucional.us.es/revistas/revistas/andaluces/htm/indice27.htm 
El cuadro 4 también proporciona otras aproximaciones, pues los centros comarcales, según definimos en el 2002 (incluyendo capitales y urbes de comarcas polinucleares y cabeceras inferiores a $5.000 \mathrm{~h}$ ) alojan casi al $60 \%$ de los andaluces (57.9) y, si consideramos sólo los mayores de 10.000 o de 20.000 h., los porcentajes respectivos serían el 56 y 52.6. Claro, que las aglomeraciones y áreas metropolitanas constituyen el $16 \%$ de la población, contando los municipios superiores a $10.000 \mathrm{~h}$., y, si se suman las ocho capitales, serían el $45.8 \%$. Más exactamente, tendríamos el $30 \%$ capitalino, que supone el 53.3 con toda la población de las aglomeraciones (a lo que debemos añadir las ciudades de Jerez, Algeciras y Marbella, esto es, aproximadamente, el $57 \%$ ), el $28 \%$ en urbes con centralidad y el $7 \%$ en el apartado "otros" (10.000-50.000). Pero los menores de 10.000 h. (aparte las cabeceras pequeñas) son el 19\%. Esto es, más redundancia de la importancia urbana de Andalucía, que se refuerza con otro aspecto, cual es el número de núcleos. Y en este sentido, 89 municipios más las ocho capitales indican muy bien la dispersión de la centralidad en las 62 comarcas o ámbitos (CANO, 2002). Y los 591 municipios inferiores a $10.000 \mathrm{~h}$. (desquitando las cabeceras comarcales), que suman un millón y medio de habitantes, suponen el $18.7 \%$ de los andaluces a una media de 2,550 por municipio. Es decir, junto con la potente urbanización (de aglomeraciones y centros comarcales), existe una dispersión rural considerable, que atañe al $76.9 \%$ de los municipios o al $80.5 \%$, si contamos todos los menores de 10.000 , aunque sean cabeceras comarcales de lugares desarticulados.

Entrando en la clasificación propuesta, el grupo de las ocho capitales es algo muy admitido y no necesita justificación, tanto por la demografía como, y sobre todo, por las diversas funciones capitalinas y la actividad económica, a lo que se une el ser (salvo el conocido caso de Córdoba por su gran extensión municipal) metrópolis de aglomeraciones. Los cuatro núcleos con más de 100.000 h. también suelen distinguirse en las publicaciones y, excepto Dos Hermanas (con funciones residenciales e industriales en el área de Sevilla, pero también con servicios propios para su población, por lo menos), se tratan de tres importantes centros comarcales, que en los casos de Jerez y Marbella forman conurbación prácticamente con la Bahía de Cádiz y Málaga-Costa del Sol, respectivamente. Algeciras, por su parte, encabeza una poblado Campo de Gibraltar con varios núcleos importantes (La Línea, San Roque...). 
CUADRO 4. LÍMITES URBANOS, 2007

\begin{tabular}{|l|c|c|}
\hline GRUPO & No MUNICIPIOS & \% POBLACIÓN \\
\hline 1.- CAPITALES DE PROVINCIAS & $\mathbf{8}$ & 29.75 \\
\hline 2.- CENTROS (comarcales y polinucleares) & & \\
\hline 2.1.-Más de 100.000 H & 3 & 5.50 \\
\hline 2.2.-50.001-100.000 H & 9 & 7.15 \\
\hline 2.3.-20.001-50.000 H & 30 & 10.20 \\
\hline 2.4.-10.001-20.000 H & 19 & 3.46 \\
\hline 2.5.- 5.001-10.000 H & 19 & 1.56 \\
\hline 2.6.-Otros centros comarcales (Menos 5.000 h) & 9 & 0.25 \\
\hline TOTAL & 89 & 28.12 \\
\hline 3.- EN ÁREAS METROPOLITANAS O AA.UU & & 1.46 \\
\hline 2.1.-Más de 100.000 H & 1 & 6.16 \\
\hline 2.2-50.001-100.000 H & 7 & 4.28 \\
\hline 2.3.-20.001-50.000 H & 13 & 4.14 \\
\hline 2.4.-10.001-20.000 H & 24 & 7.49 \\
\hline 2.5.- 5.001-10.000 H & 88 & 23.53 \\
\hline TOTAL & 133 & 7.38 \\
\hline 4.- OTROS (10.000-50.000 h) & 36 & 11.22 \\
\hline 5.- RESTO (Apartado 8, cuadro 3) & $\mathbf{5 0 3}$ & 100.00 \\
\hline ANDALUCÍA & 769 & \\
\hline
\end{tabular}

Podríamos haber agrupado todos los municipios entre 20.000 y $100.000 \mathrm{~h}$., pero hemos preferido contar con el umbral de los $50.000 \mathrm{~h}$., pues son 16 con el $13.3 \%$ de la población y merecen una consideración aparte, sin perjuicio, como se dijo, de que puedan unirse los datos en el bloque que suele considerarse ciudades medias. Hay seis centros comarcales: El Ejido, Motril, Vélez Málaga y Sanlúcar de Barrameda en la costa, más Linares y Utrera en los extremos NE y SO del Valle del Guadalquivir. Están bien distribuidos (uno en cada provincia, excepto Córdoba y Huelva) y a cierta distancia entre ellos y de grandes ciudades, salvo en el caso de Almería, con buena comunicación y no tanto en el núcleo gaditano, apartado de autovías. Siete ciudades se incluyen en cuatro aglomeraciones: Bahía de Cádiz (San Fernando, Puerto de Santa María y Chiclana), Málaga (Benalmádena y Torremolinos), Sevilla (Alcalá de Guadaíra) y Campo de Gibraltar (La Línea). Otras tres con más de 50.000 habitantes están en el grupo de ámbitos polinucleares: Roquetas del Mar con el Ejido, muy próxima a Almería, al igual que Mijas, respecto a Málaga (también podría entrar en la aglomeración), pero en la Costa del Sol, como Estepona y con una cabecera principal 
que es Marbella. Salta a la vista que, de las 16 ciudades, nada menos que 13 se localizan en el litoral.

El grupo 20.000-50.000 h. cuenta con 15 núcleos de gran importancia territorial, como los que se asientan en la Depresión Intrabética, centrando claramente comarcas: Baza, Guadix, Loja (la única con dos lugares de más de 10.000 h.) y Antequera, al igual que Ronda, más al oeste del Surco. Seis se sitúan en el Valle del Guadalquivir, bien como centros indiscutibles (Andújar, Baena, Écija) o con otras ciudades: sean polinucleares (Úbeda con Baeza,) u otras con más de 10.000 h. (Palma del Río y Carmona). En el Subbético están Morón (con Puebla de Cazalla y Marchena) y Arcos (con Villamartín y Ubrique). En la costa queda Barbate (con un centro de más de $20.000 \mathrm{~h}$, Conil) y cerca de Málaga se localiza Coín, cabecera del Valle del Guadalhorce, junto con Álora. Por lo tanto, se trata de una buena distribución, de la que sólo quedan fuera las provincias de Almería y Huelva sin ninguna en la costa, por lo que la diferenciación 20-50 y 50-100 (en miles de habitantes) es significativa. Y si contamos todo el bloque 20-50, de 49 urbes, sólo 17 (29\%) son costeras, considerando como tales a los dos Alhaurín de Málaga.

Trece núcleos entre 20.000 y 50.000 habitantes forman parte de aglomeraciones, de las que cinco están en el área de Sevilla (Camas, San Juan de Aznalfarache, Tomares, La Rinconada y Coria del Río), tres en Málaga (Rincón de la Victoria, Alhaurín de la Torre y Alhaurín el Grande), dos en Granada (Armilla y Maracena), dos en Algeciras (San Roque y Los Barrios) y uno en la Bahía de Cádiz (Puerto Real). Otras 15 urbes de 20-50.000 h. están en ámbitos polinucleares, como Adra, cabecera tradicional anterior al crecimiento de El Ejido y Roquetas, Almuñécar en la Costa granadina, Martos y Alcalá la Real en una misma comarca con dos ámbitos de ciertas diferencias (véase CANO, 2002) y Lebrija, cerca de Utrera. También Mairena del Aljarafe, cada vez con más población y servicios, cabecera de la primera línea de metro de Andalucía, Lepe (con tendencia a ser mononuclear) con Isla Cristina en la Costa Oeste de Huelva, Almonte con la Palma del Condado, Rota en la misma comarca de Sanlúcar, y sobre todo en el Subbético de Córdoba (Lucena, Priego y Cabra) y en la Campiña (Puente Genil y Montilla). En el apartado de "otros", hay seis municipios entre 20.000 y 50.000 habitantes que no son centros comarcales, mononuclear o polinuclear, ni están propiamente en aglomeraciones. Se trata de Los Palacios y Villafranca (Bajo Guadalquivir) Conil (La Janda), Fuengirola (Costa del Sol), Nerja (Axarquía), Vícar (Poniente almeriense) y Níjar (Almería, pero fuera de la aglomeración). 
Entre 10.000 y 20.000 habitantes sólo hay cuatro centros comarcales: Pozoblanco (Los Pedroches), Peñarroya-Pueblonuevo (Valle del Guadiato), Lora del Río (Vega de Sevilla) y Valverde del Camino (Andévalo oriental). En cambio, son 24 los situados en aglomeraciones de Granada (La Zubia, Albolote, Santa Fe, Atarfe, Las Gabias, Pinos Puente, Ogíjares, Huétor Vega, Peligros y Churriana de la Vega, por orden de población), Sevilla (Castilleja de la Cuesta, Bormujos, La Algaba, Gines, Brenes y Espartinas), Huelva (Moguer, Aljaraque, Punta Umbría y Gibraleón), Jaén (Torre del Campo y Mancha Real), Málaga (Cártama) y Almería (Huércal). Hay un neto predominio de núcleos interiores en una distribución desigual, de la que quedan fuera Bahía de Cádiz, Campo de Gibraltar y Costa del Sol, que comentaremos en el epígrafe siguiente.

Quince centros entre 10.000 y 20.000 habitantes se incluyen en ámbitos polinucleares: Ayamonte y Cartaya en la Costa Oeste de Huelva; Marchena y Puebla de Cazalla en la comarca Morón-Campiña; Osuna y Estepa en la Sierra Sur de Sevilla; Ubrique y Villamartín en la Sierra de Cádiz; Huércal Overa y Vera en el Levante almeriense; Baeza en Las Lomas de Úbeda; Álora en el Valle del Guadalhorce; Sanlúcar la Mayor en el Aljarafe; Albox en el Valle del Almanzora, y La Palma en el Condado de Huelva. De entre 10.000 y 20.000 habitantes hay otros 30 municipios repartidos por diversas comarcas, aunque abundan más en el Valle del Guadalquivir, Subbético y Costa, y menos en Sierra Morena (solo La Carolina), así como en interiores de Huelva, Almería y Granada.

Fuera de los límites urbanos, es decir, con menos de 10.000 habitantes, hay 28 centros en 15 comarcas, de los que 19 cuentan con más de $5.000 \mathrm{~h}$. y son: Montoro en el Alto Guadalquivir, Huéscar al norte de Granada, Cazorla en la comarca de igual nombre, Aracena y Cortegana en la Sierra de Huelva, Vélez Rubio en Almería, Iznalloz en los Montes de Granada, Dúrcal en Lecrín, Constantina y Cazalla en la Sierra Norte de Sevilla, Olula del Río en el Almanzora, compartiendo capitalidad con Albox, Montefrío y Alhama en el Poniente de Granada, Huelma en Sierra Mágina, Aznalcóllar y Gerena en el Corredor de la Plata, Nerva en Minas de Riotinto, Beas en la Sierra de Segura, y Órgiva en las Alpujarras granadinas. Esto es, como se dijo, áreas periféricas y desarticuladas.

Para completar las cabeceras comarcales quedan 9 centros (apartado 7 del cuadro 2) con menos de 5.000 habitantes en zonas periféricas y poco pobladas. Son Canjáyar (Alpujarra granadina), Tabernas en el Campo de su nombre, Santisteban del 
Puerto (con casi 5.000 h.), en el Condado de Jaén, y Puebla de Guzmán con Villanueva de los Castillejos (en "conurbación" con El Almendro) en el Andévalo Occidental. Y, si se quieren reforzar pequeñas centralidades en ámbitos desarticulados, habría que incluir a Ugijar y Cádiar (en la Alpujarra Granadina con Órgiva, que está muy al oeste), Orcera (Con Beas de Segura), y Minas de Riotinto (próximo a los 5.000 h.) con Nerva.

\section{CIUDADES Y TERRITORIOS}

\subsection{Los grandes ejes urbanos}

Es necesario analizar y explicar más la anterior clasificación en relación con los diferentes ámbitos, empezando por una aproximación a las grandes estructuras andaluzas, pues, aunque se conocen cuáles son los principales ejes urbanos, añadiremos una cierta caracterización, recordando que nos referimos al conjunto de más de $10.000 \mathrm{~h}$. y las cabeceras comarcales (mapa 1). En el Valle del Guadalquivir existe una mayor concentración de ciudades y sólo aparecen tres cabeceras con menos de 10.000: Montoro, Aznalcázar y Gerena, si bien estas dos corresponden a una comarca (Ruta de la Plata), más de voluntad político-administrativa que de realidad (CANO, 2002). Destaca mucho la presencia de las capitales de Jaén (con cierta tendencia a la formación de aglomeración), Córdoba y, sobre todo, Sevilla, la más importante área metropolitana de Andalucía. Y, si se considera como extensión del Valle a Huelva y Cádiz [el triángulo con Sevilla viene a ser el espacio más dinámico de la Comunidad (JORDÁ, 1987)], el predominio del Valle del Guadalquivir es indiscutible.

En cualquier caso, con ambas dentro de la Costa, nos encontramos con otro ámbito notable, que forma en gran parte un continuo urbano, con las dos aglomeraciones citadas, más Campo de Gibraltar, Málaga-Costa del Sol y Almería, sin ninguna cabecera con menos de $10.000 \mathrm{~h}$., lo que viene a remarcar la relevancia urbana de este eje. Quedarían como principales hiatos los siguientes. El Levante de Almería, comarca emergente; Adra-Motril, en las estribaciones de la Contraviesa; cierta disminución de densidad (aunque hay dos núcleos importantes: Estepona y Manilva), entre Marbella y San Roque, tras la abigarrada Costa del Sol; el tramo Algeciras-Barbate con Tarifa en medio y, sobre todo, la costa de Doñana entre 
Sanlúcar y Huelva. De sobra se sabe la importancia para el desarrollo litoral del turismo, la agricultura forzada y, en general, los servicios urbanos.

El Subbético es un importante eje urbano, principalmente por la existencia de fuentes cársticas, que desde antiguo han desarrollado poblaciones, la vecindad de las ricas campiñas, el casi monocultivo del olivar en zonas no muy altas y la existencia de una frontera durante dos siglos y medio (entre los reinos de Jaén, Córdoba y Sevilla, por un lado, y el estado nazarita, por otro), que también impulsó ciertos núcleos. Se trata de un conjunto de ciudades medias, sobre todo entre 20.000 y 50.000 habitantes (no hay ninguna por encima de esta última cifra) y muy pocas cabecera de menos de 10.000: Cazorla (aunque sea más bien Prebético geológicamente), Huelma, Iznalloz y Montefrío. La Depresión Intrabética es otro eje, que, salvo la aglomeración de Granada (con precedentes en el poblamiento de la Vega), presenta también ciudades medias de 20-50.000 h., típicas cabeceras comarcales a suficiente distancia en un corredor de comunicaciones desde hace siglos, hoy atravesado por la A-92. Estas ciudades son Baza, Guadix, Loja y Antequera (a lo que puede añadirse Ronda fuera de la Depresión propiamente dicha). Completan dos cabeceras comarcales con menos de 10.000 h.: Vélez Rubio, también en la autovía, y Huéscar, en parte dentro de la órbita bastetana.

Las montañas apenas tienen ciudades, destacando en Sierra Morena La Carolina, además de varios centros comarcales, dos con más de $10.000 \mathrm{~h}$., Pozoblanco y Peñarroya, y cuatro entre esa cifra y los 5.000; dos en la Sierra Norte de Sevilla y otros dos en la de Huelva. En la Penibética cuentan algunos valles, el del Guadalhorce (que se beneficia de la cercanía de Malaga, además de los regadíos, con Coín, más de 20.000 y Álora, más de 10.000), Almanzora (agrícola e industria del mármol), y Lecrín (Dúrcal). En Sierras propiamente, Órgiva (Alpujarra) $y$, en estribaciones, Alhama de Granada. En términos generales, existe una evidente diferencia entre la periferia terrestre (desde los límites con Murcia al Algarbe, pasando por Sierra Morena) y, aunque emergiendo, el litoral este almeriense, por un lado, y los grandes ejes urbanos señalados antes, por otro.

\subsection{Características provinciales}

En una primera aproximación, el conjunto urbano (superiores a 10.000 h.) más las cabeceras comarcales con menos de esa cifra arrojan un total de 178 centros 
en 62 circunscripciones y dan una media andaluza de 2.2 centros por cada 100.000 habitantes. Pero, como la máxima está en Huelva (2.7) y la mínima en Málaga (1.2), se nota enseguida la influencia del tamaño demográfico, puesto que se trata de dos provincias con distinto grado de urbanización y población total. En la parte concentrada del gráfico (1-B) aparece una distribución a escala andaluza regularmente progresiva hasta el intervalo 10.000-20.000 h., para descender bruscamente en los centros comarcales no urbanos.

La semejanza de la provincia de Sevilla con esa media no es sólo por la mayor cantidad de núcleos (22\% del total), sino porque la estructura desagregada (todos los tipos del gráfico 1-A) son parecidas. Es decir, una importante área metropolitana con núcleos del tipo 2 y 4 en cada intervalo (cuadro 3), más importantes cabeceras comarcales también en todos los grupos, salvo el 2.1, que aparece en Cádiz y Málaga. Tampoco hay cabeceras con menos de 5.000, que abundan más en zonas de la periferia desarticulada (Granada, Jaén, Huelva y Almería). Y precisamente, contemplada esa última característica, Jaén y Granada se aproximan a Sevilla en el gráfico 1-B, aunque difieren en el 1-A. El modelo granadino es de área metropolitana con núcleos más pequeños que Sevilla, y por eso destaca el grupo 5.2, y después, centros comarcales 20-50.000 h. (Baza, Gaudix, Loja) y de 5-10.000 (Huéscar, Iznalloz, etc). En cambio, la aglomeración de Jaén es menor y hay centros comarcales de diferentes tamaños, sobresaliendo el grupo 5.4 (La Carolina, Bailén, Jódar...).

Almería no se aparta mucho de la estructura media andaluza, si bien es palpable la falta de cabeceras comarcales importantes a cambio de cierta presencia en polinucleares (4.3 y 5.3) y "otros" (4.4. y 5.4.), principalmente en el Poniente y Levante. Huelva se le acerca (también capital y satélites costeros), pero, de desarrollo urbano reciente, se concentra más en las partes bajas de los intervalos (arriba del gráfico). Al revés sucede en Málaga y Cádiz, cuyas estructuras se desvían hacia las partes altas de la clasificación, de tal manera que en el conjunto considerado no hay menores de 10.000 h; esto es, un grado alto de urbanización, que abarca todas las comarcas. Incluso en Málaga no hay cabeceras con menos de $20.000 \mathrm{~h}$. (gráfico 1-A). Finalmente, Córdoba es un caso especial con una fuerte concentración de núcleos de 10.000-50.000 h. (además de la capital sin municipios periféricos de aglomeración), con abundancia de polinucleares y otros (Campiñas y Subbético, en parte agrociudades anteriores). 


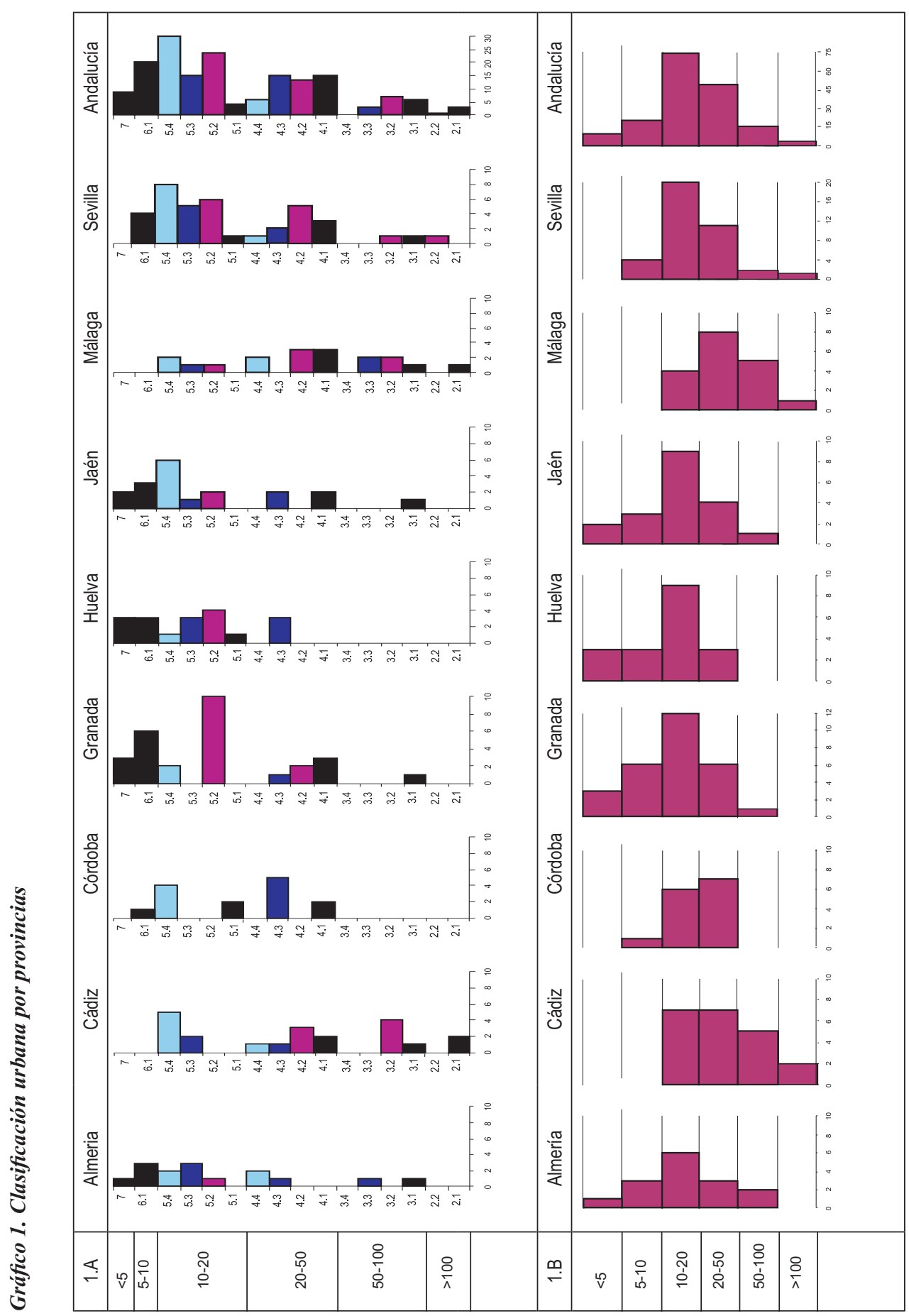

Elaboración propia. Ejecución, Antonio Gavira 
Visto de otra forma, pueden separarse las provincias litorales de las interiores. En las primeras (turismo y agricultura moderna y forzada, aparte de otras actividades urbanas, sobre todo servicios) destaca Málaga con importante aglomeración, conurbación litoral, expansión por el Valle del Guadalhorce y notables capitales comarcales interiores de raigambre (Antequera y Ronda). Cádiz carece de estas últimas (a distancia, Arcos y Ubrique), mientras en la costa destacan dos grandes aglomeraciones: Bahía de Cádiz-Jerez, incluso con la costa noroeste (Sanlúcar, Rota) de deficientes infraestructuras, y el Campo de Gibraltar. En Almería y Huelva progresan las urbanizaciones litorales a mucha distancia demográfica del interior, con despoblación junto al Algarbe y en las sierras interiores almerienses.

La costa de Granada es pequeña (pero poblada en su parte occidental, menos montañosa: Motril, Almuñécar, Salobreña) y cuenta con la aglomeración de la Vega en el interior y una serie de cabeceras comarcales bien distribuidas en la Depresión Intrabética. Las tres provincias interiores muestran los ejes urbanos del Valle y el Subbético con abundancia de núcleos y deficiencias en las Sierras, con el área metropolitana de Sevilla, una aglomeración emergente en Jaén y el aislamiento, como es sabido, del extenso municipio de Córdoba.

\subsection{Ciudades, comarcas y territorios}

Considerando lo anterior, más la tipología de comarcas que hicimos en el 2002 (CANO, pp. 78-80) y las modificaciones posteriores, podemos establecer una clasificación urbana, según los 62 ambitos (comarcas, áreas metropolitanas...) marcados en esa publicación y que constan aquí en el mapa 2. 


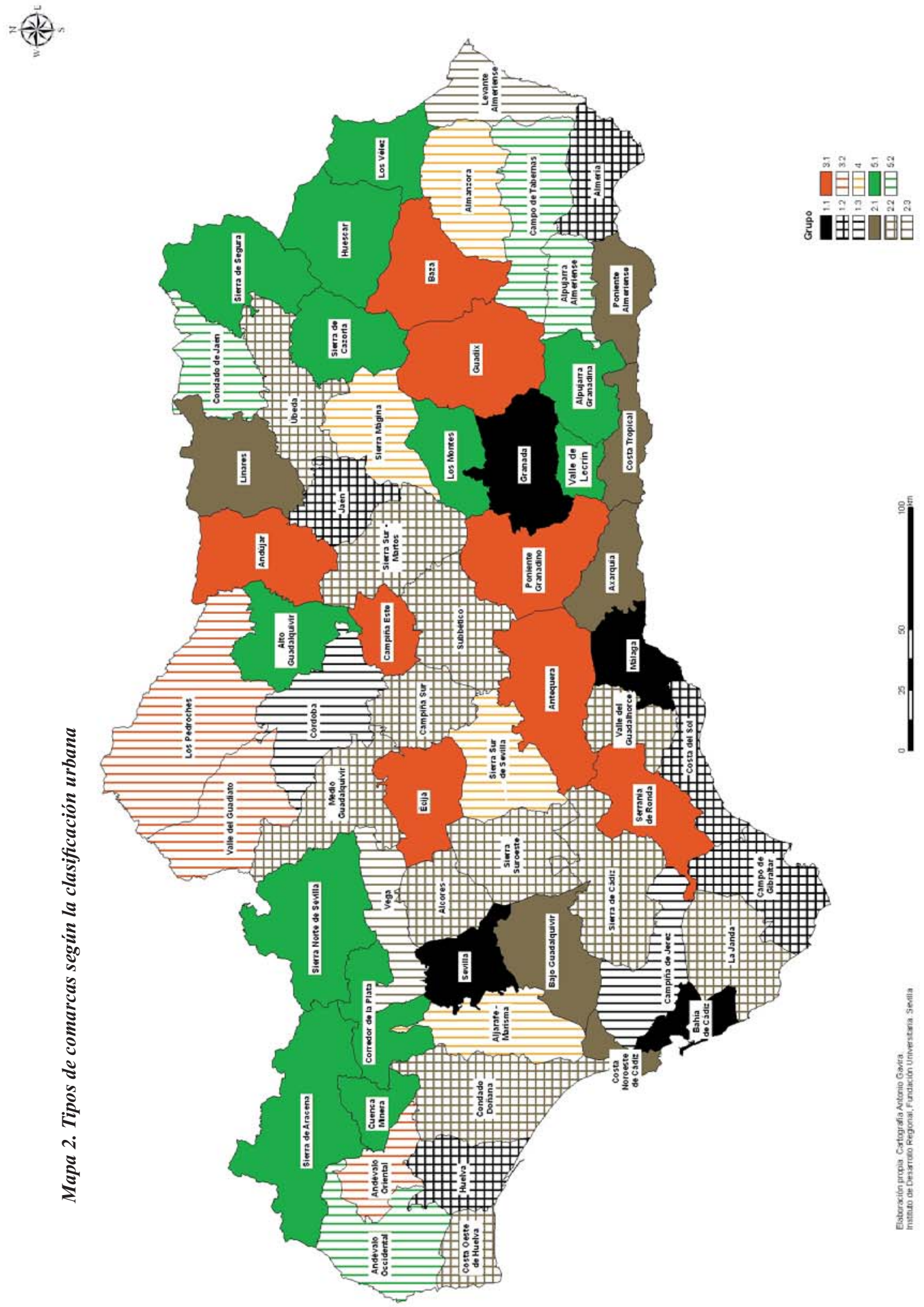


1.- Aglomeraciones, capitales y municipios mayores de 100.000 habitantes. Es el primer escalón del sistema urbano andaluz, admitido por distintos autores, como vimos, con el umbral inferior de los 100.000 habitantes, donde empezarían las ciudades medias. Son once núcleos con ciertas peculiaridades.

1.1.- Cuatro aglomeraciones urbanas con un conjunto superior a los 400.000 h. y con cuatro metrópolis (Sevilla, Málaga, Granada y Cádiz) de áreas crecientes, en las que se incluyen ciudades de diferentes tamaños, incluso más de 100.000 h. en el caso de Sevilla (Dos Hermanas), que tiene una potente periferia, producto fundamentalmente de la desconcentración. Cádiz ejerce menos de centro, por su condición de casi isla, presentándose en realidad una conurbación en la Bahía, cada vez más conectada con Jerez de la Frontera. Málaga se expande por el litoral y se une a la Costa del Sol, por el fenómeno turístico, mientras que Granada se rodea principalmente de núcleos con menos de 20.000 h., cuyos antecedentes están en el poblamiento de la Vega.

1.2.- Seis aglomeraciones con más de $200.000 \mathrm{~h}$ y centros en tres capitales de provincia, Huelva, Almería y Jaén, cuyas periferias no son comparables a las cuatro anteriores, y son de reciente expansión, sobre todo en la costa. Turismo y agricultura intensiva explican los crecimientos, aparte (no es cuestión de repetirlo mucho) las funciones urbanas, sobre todo los servicios. Las otras dos áreas están encabezadas por ciudades con más de $100.000 \mathrm{~h}$. y funciones específicas de turismo (Marbella) e industria (Algeciras).

1.3.- Quedan otra capital de provincia, Córdoba, y Jerez, que tienen más de $100.000 \mathrm{~h}$., pero no crean periferias, como en los casos anteriores, por razones de extensión municipal o cercanía a la conurbación gaditana. Y precisamente en la propuesta del 2003 (CANO), Jerez aparece como un ámbito o comarca propia, dada la ampliación de su término.

2.- Núcleos entre 10.000 y 100.000 h., que se sitúan en número de tres 0 más en un mismo ámbito, por tratarse de comarcas costeras de reciente crecimiento con nuevos centros 0 añadidos a otros tradicionales, 0 antiguas cabeceras, a veces agrociudades, con proliferación y desarrollo de otros municipios. Constituyen ya una 
parte de las ciudades medias y pueden distinguirse dos subgrupos según el tamaño de la capital comarcal.

2.1.- Cabeceras con más 50.000 h., en ámbitos que superan los 100.000 habitantes, que pueden ser centros indiscutidos, como Vélez-Málaga, Sanlúcar de Barrameda y Linares, o con una segunda "capitalidad", como El Ejido (Roquetas e incluso Adra), Utrera (Lebrija) y Motril (Almuñécar).

2.2.- Urbes con más $20.000 \mathrm{~h}$. y la misma doble clasificación, pues hay centros únicos (Barbate, Palma del Río y Carmona), aunque en sus respectivos ámbitos existan otros municipios urbanos, pero sin apenas área de influencia (CANO, 2003), como Conil, Medina Sidonia, Vejer, Fuente Palmera, La Carlota, Mairena y el Viso del Alcor. Pero hay nueve con cabecera 20-50.000 h. y otros núcleos de alguna centralidad, aparte de varios municipios urbanos en sus ámbitos. Son el Subbético cordobés (Lucena, Cabra, Priego), Sierra de Cádiz (Arcos, Villamartín, Ubrique), Sierra Sur-Martos (ámbito ya dual con Alcalá la Real y Martos), Campiña Sur (Puente Genil, Montilla), Lomas de Úbeda (Úbeda, Baeza), Morón-Campiña (también dual con Morón, Marchena y Puebla de Cazalla), Condado-Doñana (Almonte, La Palma e, incluso, Bollullos), Costa Oeste de Huelva (Lepe, Isla Cristina...), y Valle del Guadalhorce (Coín, Álora).

2.3.- Dos cabeceras con 10.000-20.000 habitantes en la Vega de Sevilla (Lora del Río, con 19.327 en el 2007, y Cantillana) y el Levante almeriense (Vera y Huércal Overa).

3.- Núcleos urbanos cabeceras de comarcas únicos en sus ámbitos, que podrían ser el paradigma de ciudad media con una clara área de influencia sin centros rivales, diferenciándose según tamaños.

3.1.- Núcleos entre 20.000 y 50.000 h. son las ciudades de Antequera, Andújar, Ronda, Écija, Guadix, Baza y Baena, a los que puede unirse Loja con la especificidad de poseer en el ámbito demarcado (tres antiguas comarcas en realidad) los núcleos de Montefrío y Alhama con menos de $10.000 \mathrm{~h}$. 
3.2.- Núcleos entre 10.000 y 20.000 h. son solo dos al norte de Córdoba, Pozoblanco (Los Pedroches) y Peñarroya (Valle del Guadiato), y uno en Huelva, Valverde del Camino.

Si atendemos al intervalo 20.000-100.000 h., las cabeceras con centralidad (grupos 2.1, 2.2 y 3.1) compondrían las ciudades medias (un total de 21) propiamente dichas, pero continúa la clasificación del conjunto anunciado.

4.- Otros núcleos urbanos o ciudades 10-20.000 h. cabeceras comarcales, pero con diferentes características. Así, con dos municipios superiores a $10.000 \mathrm{~h}$. está la Sierra Sur de Sevilla (Osuna y Estepa); con tres (Sanlúcar la Mayor, Pilas y Puebla del Río) en Aljarafe-Marisma, ámbito cada vez más en el área de Sevilla, sobre todo la parte Norte; con uno urbano, Albox, y otro inferior a $5.000 \mathrm{~h}$. en Valle del Almanzora; uno con capital en Huelma por tener mayor centralidad que Jódar (aunque ésta cuente con más de 10.000 h) en Sierra Mágina.

5.- Otras cabeceras comarcales con menos de $10.000 \mathrm{~h}$. con dos grupos según tamaños

5.1- Núcleos con más de $5.000 \mathrm{~h}$ y pequeñas centralidades en demarcaciones poco pobladas y periféricas, cuya propuesta en 2002 (CANO) obedeció a la conveniencia de delimitar para desarrollar. Están en seis ámbitos con varias cabeceras: Sierra de Segura, Alpujarra Granadina, Cuenca Minera, Sierra de Aracena, Sierra Norte de Sevilla y Corredor de la Plata. Y en otras seis comarcas con una sola centralidad: Montoro, Cazorla, Iznalloz, Dúrcal, Huéscar y Vélez Rubio.

5.2.- Pueblos con menos de 5.000 h., en cuatro ámbitos demarcados por los mismos criterios anteriores: Andévalo Occidental, Campo de Tabernas, Condado de Jaén y Alpujarra almeriense.

\section{ALGUNAS CONCLUSIONES}

Andalucía cuenta con una larga tradición urbana, cuyo resultado territorial es (excepto en algunas áreas periféricas) una buena distribución, componiendo una adecuada red de centros. Especial importancia ostentan en este sentido las ciudades 
medias, muchas veces centros comarcales, que poseen ventajas comparativas, sobre todo en el nuevo concepto de urbe intermedia, lo que implica múltiples conexiones de intercambio y cooperación a escala amplia.

Pero hay algo sin resolver, cual es la definición de la misma ciudad media hacia lo que se dirigen varios estudios, no tanto con ese objetivo, como a propósito de análisis urbanos más generales. En consecuencia, hemos abordado un epígrafe sobre el estado de la cuestión de límites y clasificaciones considerando una treintena de autores. Aunque hay bastante diversidad, se detectan algunos límites significativos, como el de 20.000-100.000 habitantes para las ciudades medias andaluzas, y, también, apreciaciones sobre el concepto de este tipo de poblamiento.

Desde hace dos décadas hemos intentado avanzar en los límites y clasificaciones con especial interés en los aspectos territoriales y en la distinción de las ciudades con centralidad, por un lado, generalmente cabeceras comarcales, y las incluidas, por otro, en aglomeraciones urbanas y áreas metropolitanas, cuya función es diferente. Así, llegamos ahora a una propuesta que abarca distintos criterios encuadrados en intervalos de población con cierta desagregación, susceptible de agrupaciones posteriores; concretamente, la variable tamaño y las funciones territoriales, distinguiéndose primero las capitales de provincia, que reúnen los dos parámetros y que generalmente inician las listas urbanas.

Los núcleos mayores de 100.000 habitantes también suelen considerarse aparte y, en el caso de Algeciras, casi alcanza las funciones capitalinas, mientras que Jerez y Marbella tienen centralidad y prolongan las aglomeraciones Bahía de Cádiz y Málaga-Costa del Sol, respectivamente (cuadro 3). Dos Hermanas, por su parte, queda en el área metropolitana de Sevilla, porque diferenciamos entre ciudades con centralidad y las que se sitúan en las periferias de las aglomeraciones. Aunque también apartamos en los grupos siguientes las cabeceras polinucleares (caso del Subbético cordobés, por ejemplo) y otras urbes con apenas centralidad, pero no incluidas en áreas metropolitanas. Así el aspecto territorial queda bastante completo, al considerar cuatro situaciones en cada intervalo demográfico y, además, se relaciona en el epígrafe 6 el sistema urbano con espacios a distintas escalas (ejes de población, provincias y ámbitos comarcales). 
En cuanto al tamaño, entre los 20.000 y los 100.000 h., en que se insertan las ciudades medias, nos ha parecido conveniente hacer límite en los 50.000 (con seis centros comarcales de importancia: El Ejido, Motril, Vélez Málaga, Sanlúcar de Barrameda, Linares y Utrera) y repartir en porcentajes similares de población (13.3 y $16.7 \%$, cuadro 3 ), que, como dijimos, siempre pueden analizarse en conjunto. En cuanto al grupo 10.000-20.000, aunque se considera urbano, puede ser discutible su categoría de ciudad media y, de hecho, sólo hay cuatro centros comarcales, mientras desagregamos cabeceras de zonas desarticuladas entre 5.000 y 10.000 habitantes e, incluso, con menos de 5.000. No serían ciudades medias, pero sí núcleos con cierta centralidad, que conviene potenciar en espacios periféricos y desarticulados.

\section{BIBLIOGRAFÍA}

BELLET y LLOP: "Ciudades intermedias entre territorios concretos y espacios globales", Ciudad y Territorio, XXXIV, 2004, pp. 569-581.

CANO GARCÍA, G.: "Jerarquización de los núcleos andaluces", Geografía de Andalucía (Dir. G. Cano), Sevilla, Edit. Tartessos, tomo VIII, 1987, pp. 186-204.

CANO GARCÍA y GARCÍA GÓMEZ: "Sistema de ciudades andaluzas", Gran Enciclopedia Andaluza (Dir. G. Cano), Sevilla, Edit. Tartessos, tomo 5, 2000, pp. $11-$

CANO GARCÍA, G.(Dir.): Las Comarcas Andaluzas, Sevilla, Edit. Tartessos, 2002, $455 \mathrm{pp}$.

CANO GARCÍA, G.: "Ciudades", Enciclopedia General de Andalucía, (dir. A. Ramos), Málaga, Ed. C y T, 2004, Tomo 6, pp.2.454-2.458.

CANO GARCÍA, G.: "Las ciudades andaluzas en el siglo XIX. Territorio y desarrollo", Revista de Estudios Andaluces, n 26,2006 , pp. 183-238.

CARAVACA BARROSO, I.: "Efectos de la globalización en el sistema urbano andaluz", Estudios Regionales, n 54, 1999, pp. 291-30. 
CARAVACA BARROSO, I. y OTRAS AUTORAS: "Hacia una Tipología de Ciudades Según su Capacidad Innovadora. Aplicación a Andalucía". A Geografía Ibérica no Contexto Europeu: Libro de Resumo Do X Coloquio Ibérico de Geografía. Coloquio Ibérico de Geografía. Num. 10. Évora (Portugal). Universidade Do Evora. 2005, pp. 119-120.

CONSEJERÍA DE POLITICA TERRITORIAL. Propuesta de Comarcalización, $195 \mathrm{pp}$.

CONSEJERÍA DE OBRAS PÚBLICAS Y TRANSPORTES: Jornadas sobre ciudades medias (1990), Sevilla, 1991, 250 pp.

BRAVO Y PAREJO

CASASSAS SIMÓ

LÓPEZ CHACÓN

MONTEAGUDO LÓPEZ-MENCHERO

ZOIDO NARANJO

CONSEJERÍADE OBRAS PÚBLICASY TRANSPORTES: Plan de Ordenación del Territorio de Andalucía, 2006.

DE ESTEBAN y LÓPEZ: "El papel de las ciudades medias en España. Presente y futuro", Revista del Colegio Oficial de Arquitectos de Madrid, $n^{0} 5$, 1989, pp. 6-16.

DÍAZ QUIDIELLO, J.L.: "Écija una ciudad histórica bajo el signo de la arquitectura", Boletín del Instituto de Patrimonio Histórico, n⿳0 38.

ESCALERA, J. y RUIZ BALLESTEROS, E.: "Asociacionismo vecinal en las ciudades medias andaluzas", Revista de Estudios Andaluces, 26, 2006, pp. 37-66.

FERIA TORIBIO, J.M.: "El sistema urbano andaluz", Geografía de Andalucía (Dir. G. Cano), Sevilla, Edit. Tartessos, tomo III, 1987, pp. 259-352. 
FERIA TORIBIO, J.M.: El sistema urbano andaluz, Sevilla, Instituto de Desarrollo Regional, 1992, 309 pp.

GANAU, J. y VILAGRASA, J.: "Ciudades medias en España. Posición en la red urbana y procesos urbanos recientes", en Ciudades, arquitectura y espacio urbano, Barcelona, Caja Rural Intermediterránea, 2003, pp.37-73.

JORDÁ BORRELL, R.: "Población, economía y territorio en Andalucía", Geografía de Andalucía (Dir. G. Cano), Sevilla, Edit. Tartessos, tomo III, 1987, pp.137-206.

JORDÁ BORRELL y GONZÁLEZ RELAÑO: "Binomio innovacióninternacionalización y su relación con la estrategia en las empresas innovadoras andaluzas", Revista Scripta Nova, Barcelona, 2009.

LÓPEZ ONTIVEROS, A.: "La agrociudad andaluza: caracterización, estructura y problemática”, Estudios Regionales, n³9, 1994, pp. 59-91.

LLOP TORNÉ (Director): Ciudades intermedias y urbanización global, Ayuntamiento de Lleida, UNESCO, UIA, Ministerio de Asuntos Exteriores, 1999.

MALLARACH y VILAGRASA: "Los procesos de desconcentración urbana en las ciudades medias españolas", Ería, 57, 2002, pp. 57-70.

MÉNDEZ, R. (DIR): Dinámica de las ciudades medias de Andalucía, Sevilla, Instituto de Estadística de Andalucía, 2007. 134 pp.

OCAÑA, M.C. y NAVARRO, S.: "Núcleos de población de volumen medio en Andalucía", Departamento de Geografía, Universidad de Málaga, Biblioteca virtual Miguel de Cervantes de Alicante, 2005. PERO EDICIÓNN DIGITAL 1996.

OCAÑA OCAÑA, M.C.: Áreas sociales urbanas. Observaciones sobre las ciudades andaluzas, Universidad de Málaga, 1998, 255 pp. 
PEZZI CERETTO, M.: La comarcalización de Andalucía, Universidad de Granada, 1982, 183 pp.

RODRÍGUEZ MARTíNEZ, F.: "Las ciudades medias andaluzas. Cambios básicos durante el último medio siglo", Homenaje a Joaquín Bosque Maurel, coord. Por J. Bosque Sendra, 2008, pp. 199-238.

SERRANO MARTÍNEZ, J.M.: "Crecimiento y consolidación de las principales aglomeraciones urbanas españolas", Investigaciones geográficas, $n^{0} 44$ (2007), pp. 33-54.

SALOM CARRASCO, J.:"Ciudades medias y centros intermedios en el Arco Mediterráneo", Las ciudades españolas a finales del siglo XX. I Coloquio de Geografía Urbana, Campesino (Coord.), Universidad Castilla La Mancha, 1995, pp. 53-56.

VALENZUELA MONTES, L. M. Accesos y forma urbana en las ciudades medias andaluzas, Tesis doctoral, Granada, 2000, 607 pp.

VILAGRASA IBARZ, J.: "Las Ciudades pequeñas y medias en España", La ciudad: tamaño y crecimiento. III Coloquio de Geografía Urbana, R. Domínguez, Coord, 1999, pp. 19-49.

VILAGRASA IBARZ, J.: "Ciudades medias e intermedias: posicionamiento en la red urbana y procesos urbanos recientes", Curso doctorado Universidad de Lleida, 2004. 